\title{
Anticancer and antibacterial effects of a clove bud essential oil-based nanoscale emulsion system
}

This article was published in the following Dove Press journal:

International Journal of Nanomedicine

\author{
M Joyce Nirmala' \\ Latha Durai ${ }^{2}$ \\ Vineet Gopakumar' \\ R Nagarajan'
}

'Department of Chemical Engineering, Indian Institute of Technology Madras, Chennai 600036, Tamil Nadu, India; ${ }^{2}$ Department of Biotechnology, Bhupat and Jyoti Mehta School of Biosciences, Indian Institute of Technology Madras, Chennai 600036, Tamil Nadu, India
Correspondence: $M$ Joyce Nirmala Department of Chemical Engineering, Indian Institute of Technology Madras, Chennai 600036, Tamil Nadu, India Tel +91 9677174200

Email joycegitz@gmail.com
Background and purpose: The essential oil derived from clove buds (Syzygium aromaticum) has been used as a chemopreventive agent in Ayurvedic medicine. The antiviral, antibacterial, and anticancer properties of its chemo-skeleton have motivated this study to explore its efficacy in pharmaceutics.

Methods: Nanoscale-based emulsions were prepared by employing a spontaneous emulsification technique through self-assembly using varying concentrations of Tween 20 and Tween 80 surfactants. Their physicochemical properties and stability were studied in order to choose an optimum formulation which was clear and stable. The cytotoxicity of the stable oil-based emulsion system was evaluated using MTT assay, colony formation assay, and Annexin V-FITC assay against the thyroid cancer cell line (HTh-7).

Results: All three methods verified apoptosis and reduction in cancer cell proliferation, making the formulation a promising candidate as an alternative cancer drug. The oil-based emulsion system was also tested for its antibacterial properties against Staphylococcus aureus. Membrane permeability studies proved its efficacy to permeate through cell membrane, thereby increasing the leakage of cytoplasmic contents.

Conclusion: Many current treatments for cancers are aggressive yet ineffective. This study positions the clove bud-based nanoscale emulsion as a suitable candidate for further in vivo studies and trials as a cancer drug.

Keywords: clove bud oil, nanoscale emulsion system, thyroid cancer, apoptosis, antibacterial activity

\section{Introduction}

Cancer is the second largest cause of death, one which has claimed in excess of six million lives annually. ${ }^{1}$ Its complexity and multifactorial nature have drawn more attention toward itself in the pharmaceutical industry. In 2018, 1.1579 million cancer cases were reported out of which 0.784 million succumbed to the disease. ${ }^{2}$ The mortality of cancer patients is higher in economically developing countries owing to the lack of standard means of treatment, basic diagnosis, and affordable treatment. This has driven researchers to develop synthetic drugs that can inhibit the growth of rapidly dividing cells, but these also lead to side effects which minimize the drug's overall efficacy. Studies have shown that chemotherapy, which has proven to be the sought-after treatment for cancer patients, also induces multidrug resistance in the human body. ${ }^{3,4}$ Medicinal therapeutics has thus reached a juncture where researchers have to look for alternative forms of treatment and different chemical pathways. Thyroid cancer has been reported as the most common endocrine-related cancer by The National Cancer Institute. While the antimicrobial properties of plant-based essential oils (EOs) have been assessed by various studies and their efficacy is proven in pharmaceutical applications, there is an urgent need 
for a more cost-effective mode of treatment for cancer. Hence, investigations into their antimicrobial and anticancer properties have regained momentum. ${ }^{5-10}$

EOs are concentrated hydrophobic liquids which are lipophilic in nature, thereby enabling them to easily cross the membrane of cells. While therapy through EO cannot entirely substitute for chemotherapy or synthetic drugs, they can mitigate the associated side effects thereby reducing fatalities and mortality rate in cancer patients. ${ }^{11,12}$ EOs are deemed to be suitable owing to their synergistic and selective effects. While the study of anticancer properties dates back to the $1960 \mathrm{~s}$, more than $85 \%$ of the research publications have appeared after 2006, indicating a sudden surge of interest in this topic. EOs and their constituents have been shown to display cytotoxic effect in the cancer cell lines of mouth, lung, prostate, liver, breast, and brain cancer. ${ }^{13-18}$ They induce cell cycle arrest, or apoptosis, which is manifested through multiple signal pathways, activation of detoxifying enzymes, destruction of DNA due to the oxidative stress, and anti-metastasis. ${ }^{19}$ Their cytotoxic effect shows minimal apoptosis in normal cells, thereby enhancing the efficacy of its antiproliferative activity.

Studies have shown that a rapid increase in resistance of multidrug pathogens toward antibiotics has constrained the availability of effective treatment options. ${ }^{20}$ This aspect gained more visibility after the World Health Organization published a report in 2014 on antimicrobial resistance (AMR). Staphylococcus aureus, a gram-positive bacteria commonly present in the respiratory tract and skin of humans and animals, has been reported to have increased its resistance by $3 \%$ over the past 5 years. ${ }^{21}$ Hence, proving the antibacterial efficacy of essential oils would be a big step toward treatment of associated infections. ${ }^{22}$ Essential oils damage the bacterial cell wall, thereby increasing cell permeability and inducing bacteriostasis. ${ }^{23}$

In this study, the anticancer and antimicrobial properties of the essential oil derived from clove buds (Syzygium aromaticum) have been investigated. Earlier studies have shown its utility as a chemopreventive agent in Ayurvedic medicine, apart from its primary role as a spice in the traditional Indian kitchen. ${ }^{24}$ The essential oils present in it are eugenol, caryophyllene, alpha-humulene, eugenyl, naphthalene, sesquiterpenes, methyl salicylate pinene, and traces of other phenolic components. ${ }^{25}$ Eugenol is the main component constituting $81.1 \%$ of the oil. Eugenol is used as an antiseptic, antibacterial, and analgesic agent in traditional medicine. Studies have reported its role in photochemical reactions and its anti-inflammatory, insecticidal, antiviral, and antioxidant properties, which make it a promising candidate for the chemical skeleton in pharmaceutical products. ${ }^{26-32}$ In this study, a nanoemulsion of the plant-based EO has been used in view of its versatile properties such as stability, larger surface area, and higher bioavailability. ${ }^{33}$ Nanoscale oil-based emulsions increase the drug retention time in the target region while causing minimal toxic side effects. Less amount of drug is required because of better penetration, increased bioavailability, higher retention time, and low drug loss during cell lysis, rendering it a promising alternative for drug delivery. ${ }^{34}$

\section{Materials and methods Materials}

Clove bud essential oil of Indian origin was purchased from Cyrus Enterprises, Chennai, India. The non-ionic surfactants, Tween 20 and Tween 80, were obtained from Merck, India. MTT was purchased from HiMedia Laboratories. Annexin V-FITC Early Apoptosis Detection Kit was purchased from Cell Signaling Technology, Inc. Double-distilled milli-Q (Millipore Corporation) water was used for all formulations.

\section{Preparation}

The standard titration technique was used to prepare the microemulsions. Oil was titrated against the surfactant in aqueous phase at laboratory temperature to make formulations of varying oil:surfactant ratios, ranging from 1:1 to $1: 9$, and $1: 9$ to $9: 1$. A constant stirring rate of $500 \mathrm{rpm}$ was maintained to prepare all samples.

\section{Stability}

The test for stability under extreme stress conditions was conducted through centrifugation (REMI International, India). The samples were allowed to naturally phase separate in the first $24 \mathrm{hrs}$, and centrifugation was carried out at $3500 \mathrm{rpm}$ for $30 \mathrm{mins}$. The formulations that passed the phase separation test were further tested for thermodynamic stability by recursive heating and cooling cycles between $45^{\circ} \mathrm{C}$ and $4^{\circ} \mathrm{C}$, and $25^{\circ} \mathrm{C}$ and $-4^{\circ} \mathrm{C}$. The formulations that passed this test were labeled as stable and carried forward for characterization studies.

\section{Characterization}

\section{Dynamic light scattering (DLS)}

DLS technique effectively measures the translational diffusion coefficients of nanoparticles and colloids, as well as 
the particle size distribution of the given sample. The underlying principle of the technique is that particles move randomly in gas or liquid in Brownian motion. One of the first descriptions of the DLS apparatus setup was published by W.I. Goldburg. ${ }^{35}$ To determine the particle size, it is necessary to correlate the intensity of the scattered light measured by the photodetector to the diffusion coefficient of the particles. This method helps determine the polydispersity index, which, in turn, characterizes the homogeneity and stability of the system. ${ }^{36}$

The droplet size and polydispersity index for all the formulations were measured by DLS using a Particle Size Analyzer (Horiba, Nanopartica SZ-100 series). The preparations were diluted with water before the measurements to negate the effects caused by multiple scattering. The measurements were carried out in triplicate with mean \pm SD calculated.

\section{Turbidity}

The absorbances of all formulations were recorded using a UV spectrophotometer (V-360 Series, Jasco Analytical Instruments, Asia) with triplicate mean $\pm \mathrm{SD}$ measurements.

\section{Viscosity}

The viscosity of the formulations (undiluted) was measured using Brookfield Viscometer with Brookfield Rheocalc Software (DV-II+ Pro EXTRA (LV-II, UL Adapter)) at $25 \pm 1^{\circ} \mathrm{C}, 60 \mathrm{rpm}$. The measurements were carried out in triplicate with mean $\pm \mathrm{SD}$ calculated.

$\mathrm{pH}$

The $\mathrm{pH}$ of the formulations (undiluted) was examined using Digital $\mathrm{pH}$ meter (EUTECH Instruments, Oakton, Singapore) at $25 \pm 1^{\circ} \mathrm{C}$. The measurements were done in triplicate with mean $\pm \mathrm{SD}$ calculated.

\section{Anticancer activity}

\section{Cell culture}

HTh-7 (Thyroid cancer cell line) and HeK-293 (nontumorigenic) cell lines were obtained from Adayar Cancer Institute, Chennai, India. HTh7 cells were propagated in RPMI 1640 media and HeK-293 cells were propagated in DMEM media supplemented with 10\% FBS at $37^{\circ} \mathrm{C}$ in $5 \% \mathrm{CO}_{2}$ and Penicillin (100 units $/ \mathrm{mL}$ )/streptomycin $(100 \mu \mathrm{g} / \mathrm{mL})$ (Gibco, Grand Island, NY, USA).

\section{MTT assay}

The percent cell viability was estimated using the MTT [3-(4, 5-dimethylthiazol-2-yl)-2,5-diphenyltetrazolium bromide] assay. ${ }^{37}$ The thyroid cancer cells were allowed to adhere for a day in $\mathrm{CO}_{2}$ incubator at $37^{\circ} \mathrm{C}$ in 96 -well plates cultured in RPMI 1640 media, and then treated with increasing concentration of the optimized clove bud emulsion formulation (CB-4). After a 48-hr treatment, the supernatant was removed and MTT solution with a concentration of $5 \mathrm{mg} / \mathrm{mL}$ was added to the suspension in the cell wells. This was incubated for $3 \mathrm{hrs}$, after which the supernatants were discarded and DMSO was added to each well. Absorbance of the crystals formed after solubilization of DMSO was measured using a microplate reader at $570 \mathrm{~nm}$. The cell viability was evaluated using this assay, and the percentage inhibition was calculated using the absorbance values of control and treated cells. ${ }^{38}$ The $\mathrm{IC}_{50}$ values - the concentration at which $50 \%$ of the cell lysis takes place - was used to measure cytotoxicity. ${ }^{39}$

\section{Colony formation assay}

This assay also called as clonogenic assay is based on the ability of a single cell to grow into a colony. ${ }^{40}$ In this assay, the HTh-7 thyroid cancer cells are grown in the 6-well plates with 1000 cells per well. The cells are then incubated in $2 \mathrm{~mL}$ of RMPI 1640 at $37^{\circ} \mathrm{C}$ for $7-10$ days after being treated with the optimized concentration of CB-4. The cells are then fixed with methanol before being stained with Crystal violet.

\section{Annexin V-FITC assay}

The apoptotic capability of the oil-based emulsion was studied by staining the treated cells with Annexin V-FITC and Propidium Iodide (PI). The HTh-7 cells were plated in $25 \mathrm{~cm}^{2}$ flasks with a density of $1 \times 10^{5}$ cells. This was followed by incubation with the $\mathrm{IC}_{50}$ values of $\mathrm{CB}-4$ for 48 hrs. Cells were finally collected after centrifugation, washed with phosphate-buffered saline, and resuspended in the Annexin buffer. Aliquot of cells $(96 \mu \mathrm{L})$ were incubated with conjugated fluorescein isothiocyanate and then stained with $12.5 \mu \mathrm{L}$ of PI to be incubated again in the dark for 10 mins. The cells were then vortexed, diluted to 250 $\mu \mathrm{L} /$ assay, and then analyzed using a BD FACSVERSE flow cytometer with an in-built BD FACSuite ${ }^{\mathrm{TM}}$ Software.

\section{Antibacterial activity}

$S$. aureus was used as the bacterial pathogen to test the antibacterial efficacy of the oil-based emulsion. It is maintained in agar slants at $4^{\circ} \mathrm{C}$ and then incubated for $18-24 \mathrm{hrs}$ at $35^{\circ} \mathrm{C}$. The agar well diffusion assay and membrane integrity studies are common methods to test for the antibacterial capabilities of a compound. A total of $100 \mu \mathrm{L}$ of the cell inoculum is inoculated and spread over the agar surface. A hole with a 
diameter of 6-8 $\mathrm{mm}$ is punched on the surface over which 20 $100 \mu \mathrm{L}$ of clove bud oil and its respective emulsion (CB-4) is placed. The plates are incubated and the phytochemical compound diffuses into the medium. On diffusion, the compound inhibits the growth of the pathogen. The diameter of the zone of inhibition is measured to evaluate its antibacterial efficiency. ${ }^{41}$ Membrane permeability studies were conducted to reinforce the findings in the diffusion assay. The culture was resuspended using the phosphate-buffered saline diluted with $9.5 \mathrm{~mL}$ of clove bud oil and CB-4, respectively, and used as the negative control. ${ }^{42}$ All samples were incubated and then centrifuged for 10 mins to push the cytoplasmic contents out of the cells. A UV-Vis spectrometer was used to measure the absorbance of the supernatant at $260 \mathrm{~nm}$.

\section{Statistical analysis}

Each experiment was repeated at least three times. Concentration-dependent curves and statistical analyses were done with GraphPad Prism 4.0 (GraphPad Software, Inc., San Diego, CA). Analyses included mean \pm SEM, oneor two-way ANOVA, and Bonferroni post-test wherever appropriate $\left({ }^{*} P<0.05 ; * * P<0.01\right.$; and $\left.{ }^{* * *} P<0.001\right)$.

\section{Results}

\section{Preparation of nanoscale emulsion system} Spontaneous self-emulsification technique

The organic phase was prepared by mixing oil and surfactant in different ratios $(\mathrm{v} / \mathrm{v})$ and the organic phase was then added dropwise to water. The emulsion was formed spontaneously with no externally applied agitation. This phenomenon has been attributed to the formation of liquid crystalline phases near the contact surface between oil and water. ${ }^{43}$ The formulations using Tween 20 and Tween 80 as surfactant are shown in Table 1, and the respective images in Figure 1. All the images were taken after 24 hrs of preparation. Visual changes in the sample from turbid to transparent, and vice versa, were observed to determine the endpoint of the compositions. The milky white or turbid mixtures that eventually phase separated within a few hours were termed as biphasic. Clear, transparent, and low-viscous mixtures that formed within a few seconds with no phase separation were termed as monophasic. From the endpoint compositions of the titrated samples, various concentrations of the components (clove bud oil, surfactant (Tween 20/Tween 80 ), and water) were plotted on the triangular coordinates of a phase diagram.

\section{Phase diagram analysis}

The phase diagram yields insight into the phase behavior of a defined mixture and its varying compositions. Ternary phase diagrams were constructed using clove bud oil as the oil phase, Tween 20 with a hydrophilic lipophilic balance (HLB) value of 16.7 and Tween 80 with an HLB value of 15.0 as surfactants, and water as the aqueous phase as seen in Figure 2. The different concentrations using either Tween 20 or Tween 80 (Table 1) as surfactants

Table I Clove bud oil formulations with Tween 20 (CB) and Tween 80 (CBO) surfactant, respectively, reported against their visual appearance

\begin{tabular}{|c|c|c|c|c|}
\hline Formulation code & Oil & Surfactant & Water & Appearance \\
\hline CB-I, CBO -I (I:I) & 5 & 5 & 90 & Milky white \\
\hline CB-2, CBO - 2 (I:2) & 5 & 10 & 85 & Cloudy \\
\hline CB-3, CBO - 3 (I:3) & 5 & 15 & 80 & Cloudy \\
\hline CB-4, CBO - 4 (I:4) & 5 & 20 & 75 & Clear and transparent \\
\hline CB-5, CBO - 5 (I:5) & 5 & 25 & 70 & Clear and transparent \\
\hline CB-6, CBO - 6 (I:6) & 5 & 30 & 65 & Clear and transparent \\
\hline CB-7, CBO - 7 (I:7) & 5 & 35 & 60 & Clear and transparent \\
\hline CB-8, CBO - 8 (I:8) & 5 & 40 & 55 & Clear and transparent \\
\hline CB-9, CBO - 9 (I:9) & 5 & 45 & 50 & Clear and transparent \\
\hline CB-10, СВO - $10(2: 8)$ & 10 & 40 & 50 & Clear and transparent \\
\hline CB-II, CBO - II (3:7) & 15 & 35 & 50 & Clear and transparent \\
\hline CB-12, CBO - $12(4: 6)$ & 20 & 30 & 50 & Milky white \\
\hline CB-I3, CBO - I3 (5:5) & 25 & 25 & 50 & Milky white \\
\hline CB-I4, CBO - I4 (6:4) & 30 & 20 & 50 & Milky white \\
\hline CB-I5, СBO - I5(7:3) & 35 & 15 & 50 & Milky white \\
\hline CB-16, СBO - $16(8: 2)$ & 40 & 10 & 50 & Milky white \\
\hline CB-I7, CBO - I7(9:I) & 45 & 5 & 50 & Milky white \\
\hline
\end{tabular}




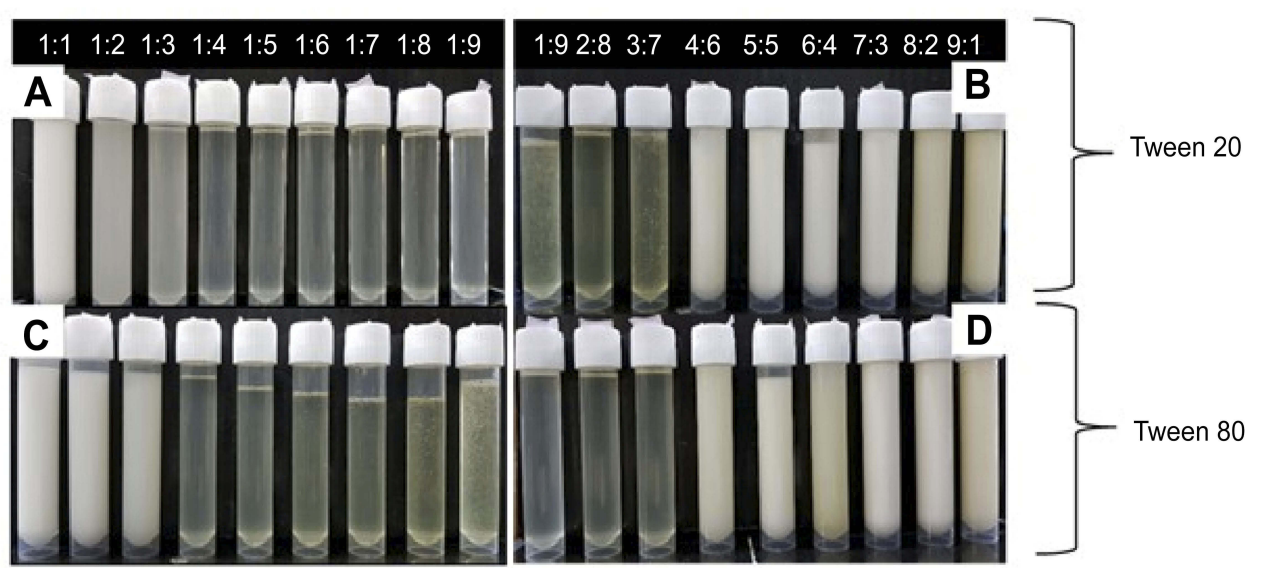

Figure I Images of formulations from I:I to 1:9 and 1:9 to 9:1, respectively, of the nanoscale emulsion of clove bud oil in Tween 20 and Tween 80 surfactant.
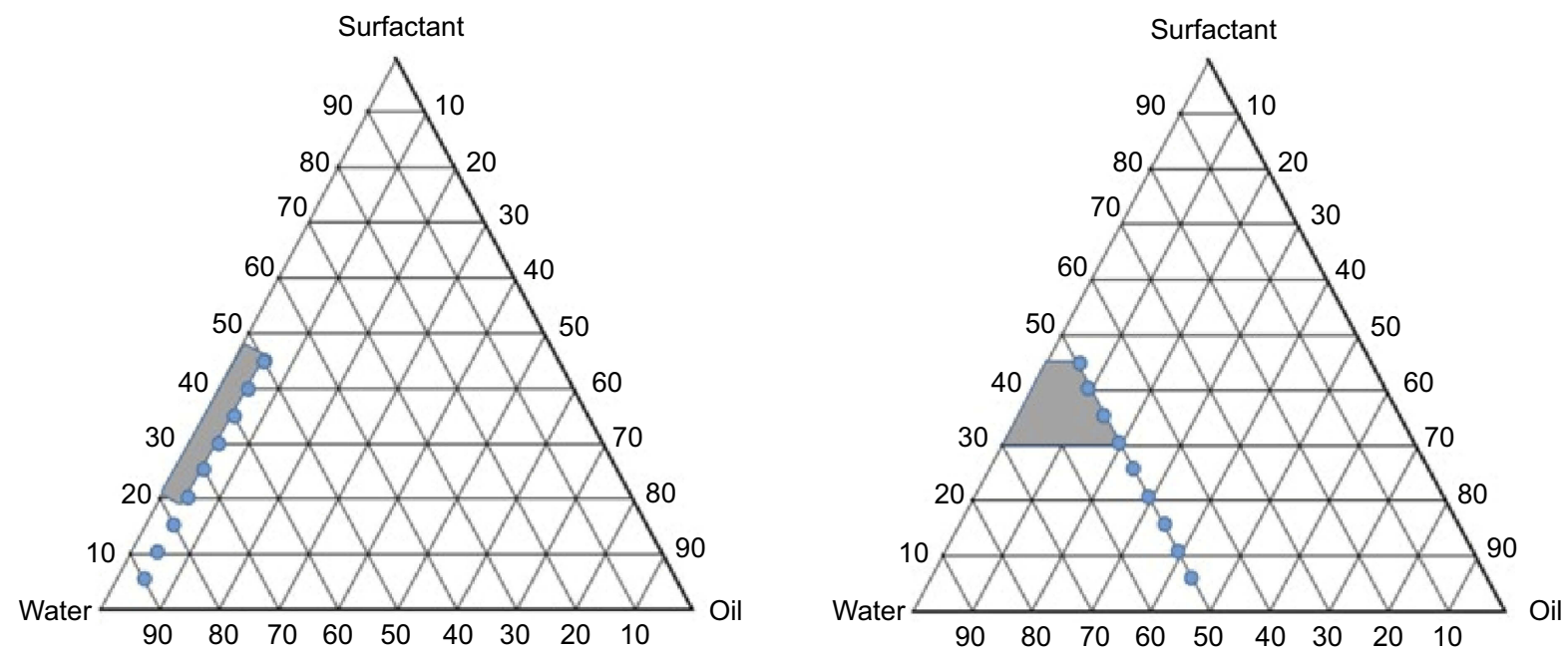

Figure 2 Ternary phase diagram constructed using clove bud oil, Tween 20 , and 80 , respectively, and water showing oil/water microemulsion region varying oil:surfactant ratio from I:I to 1:9 (left), and from 1:9 to 9:I (right) for both Tween 20 and Tween 80.

are shown in Figure 2. Both the formulations, using Tween 20 and Tween 80 , showed a similar pattern. Only the area covered by the monophasic region was shaded and termed as the microemulsion existence region. All experiments were done in triplicate to ensure reproducibility.

\section{Microemulsion characterization Droplet size distribution}

The DLS technique is well suited for the study of colloidal dispersions. The droplet size of the optimized thermodynamically stable formulation CB-4 (Figure 3) is measured without dilution, as dilution may alter the structure. The average mean droplet size of CB-4 was found to be 11.73 $\pm 0.32 \mathrm{~nm}$. The size distribution was found to be in the range of 6-27 nm. The CB-4 formulation showed a polydispersity index of $0.057 \pm 0.004$, implying good stability.
The polydispersity index measurement confirms homogeneity and stability of the formulation. The lower the polydispersity index, the more stable is the microemulsion formed. ${ }^{44}$ The size distribution also gives useful information regarding the mechanism that governs the stability of the microemulsion formed. ${ }^{45}$

\section{Stability}

Those formulations with no phase separation, indicating long-term stability, were taken for further analysis. The samples underwent recursive heating and cooling cycles to check for thermodynamic stability after being centrifuged. The samples that passed centrifugation - CB-4-CB-11 and CBO-4-CBO-11 - were checked at $4^{\circ} \mathrm{C}, 25^{\circ} \mathrm{C}$, and $45^{\circ} \mathrm{C}$ for a period of 1 month and were taken for further optimization and application studies. 


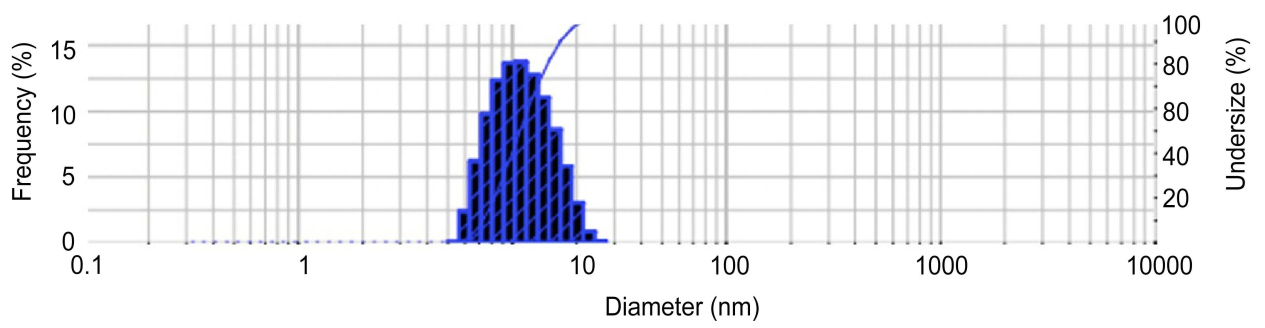

Figure 3 Droplet size distribution of the optimized formulation CB-4 (clove bud microemulsion formulation with oil: surfactant [Tween 20] ratio of I:4) showing the particle size in the nanometer range using dynamic light scattering technique.

\section{Physicochemical characterization}

The emulsion in Tween 20 was selected for characterization studies because of its lower viscosity which makes the emulsion more suitable for oil-in-water formulations in drug delivery application. The formulations were studied for $\mathrm{pH}$, viscosity, and turbidity. The findings are as given below. $\mathrm{pH}$ was observed to increase with the increase in surfactant concentration (Figure 4).

The UV-Spectroscopic measurements at $600 \mathrm{~nm}$ act as an indicator of the turbidity of the formulations. The absorbance is observed to have decreased with an increase in surfactant concentration (Figure 5).

Surfactant concentration also demonstrated a positive correlation with viscosity. With increasing surfactant concentration, there was an increase in viscosity as shown in Figure 6 .

For further anticancer and antibacterial assays, the nanoscale oil emulsion in Tween 20 surfactant was chosen (oil:surfactant ratio of 1:4 (CB-4)) amongst all the samples that passed the stability studies. CB-4 formulation was selected based on the minimum utilization of surfactant concentration with reduced droplet size.

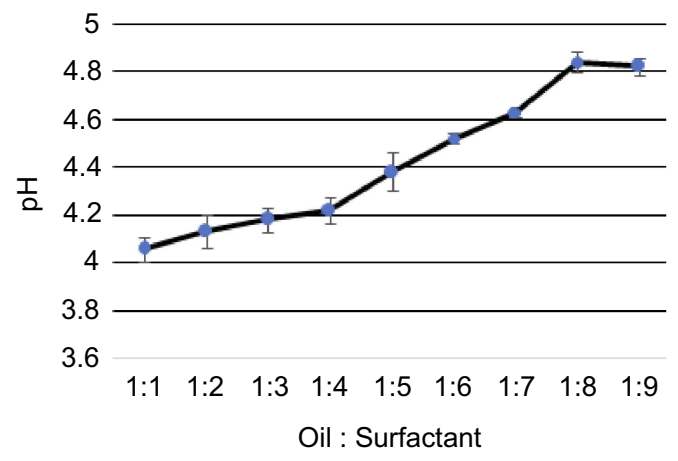

Figure 4 Variation of $\mathrm{pH}$ with oil:surfactant ratio (I:I to $I: 9)$ for the oil-based nanoscale emulsion in Tween 20 surfactant.

\section{Anticancer activity MTT assay}

The antiproliferative effect of the optimized clove bud nanoscale emulsion system (CB-4) was evaluated using

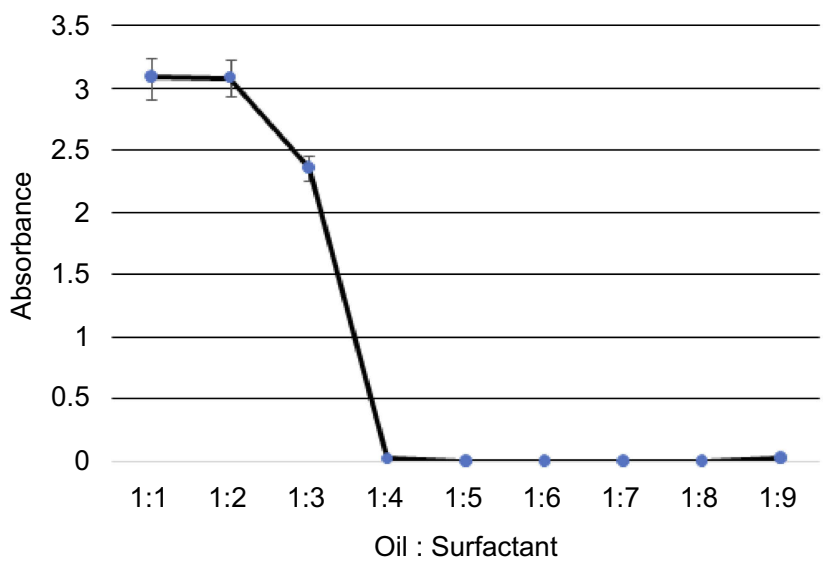

Figure 5 Variation of absorbance measured by the UV-Spectrophotometer with oil: surfactant ratio ( $1: 1$ to $1: 9)$ for the oil-based nanoscale emulsion in Tween 20 surfactant.

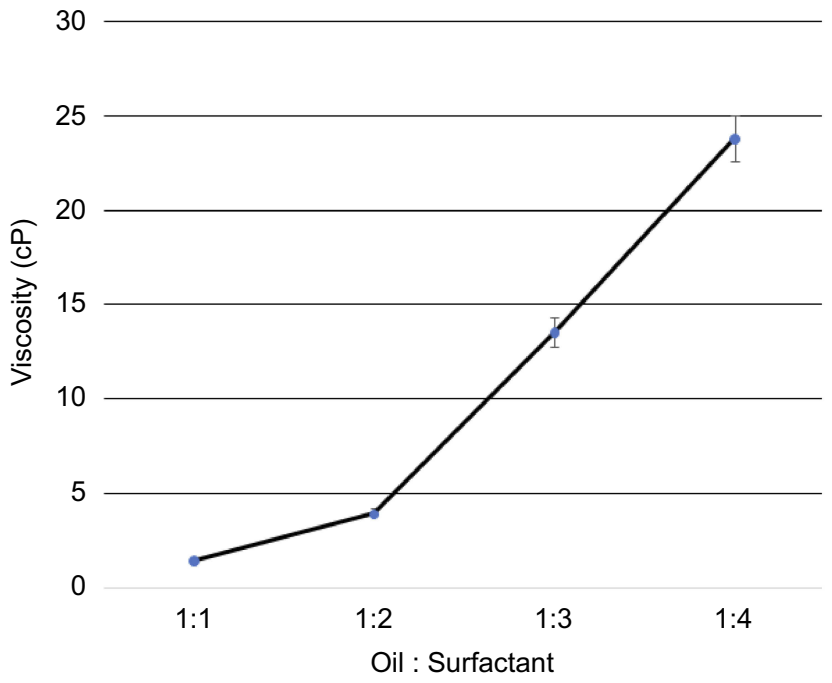

Figure 6 Variation of viscosity measured by the Brookfield viscometer with oil: surfactant ratio ( $1: 1$ to $1: 4)$ for the oil-based nanoscale emulsion in Tween 20 surfactant. 
the MTT assay. The MTT test results revealed that the formulation expressed cytotoxicity against (HTh-7) thyroid cancer cell lines. Also, the cytotoxic activity of oilbased emulsion system (CB-4) was measured in noncancerous cell line Hek-293 as well in thyroid cancerous cell line HTh-7 using MTT assay as shown in Figure 7A and $\mathrm{B}$, in which it has been found that CB-4 acts as an anticancer drug in cancer cells and exhibits no cytotoxic activity in noncancerous cells.

In the scenario of HTh-7, less than $55 \%$ of the cell death on an average was observed after a 48-hr treatment with $0.7 \mu \mathrm{L} / \mathrm{mL}$ concentration of the optimized formulation (CB4). The $\mathrm{IC}_{50}$ value of the optimized system was therefore found to be $0.7 \mu \mathrm{L} / \mathrm{mL}$ concentration of the optimized formulation for thyroid cancer cell line, as shown in Figure 7B. The effect of surfactant and water mixture was also checked as a vehicle control, and it was confirmed that they did not play any role in causing cytotoxicity.

\section{Colony formation assay}

Colony formation assay was used to determine the antiproliferative effect of clove bud oil-based microemulsion in human thyroid cancer cells HTh-7 at $\mathrm{IC}_{50}$ concentration. As shown in Figure 8A and B, the number of HTh-7 cell colonies underwent a significant reduction when treated with clove bud oil-based nanoscale emulsion system for $7-$ 10 days.

\section{Annexin V-FITC assay}

The Annexin V-FITC assay verified that the clove bud oil-based emulsion has an antiproliferative effect on the

\section{A}

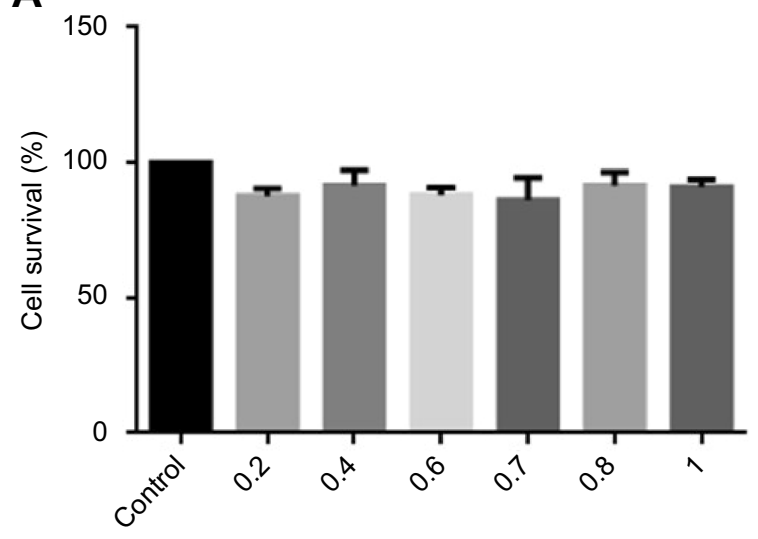

Hek 293
HTh-7 cell line growth. This assay indicates that the apoptotic cells are mainly responsible for cell death. Necrosis is also seen to some extent (Figure 9A and B). The expression of phosphatidylserine occurs through the binding of Annexin V-FITC to the cancer line cell surface indicated apoptotic cells. ${ }^{46,47}$ Further staining with propidium iodide, a non-permeable DNA dye, indicated necrotic cells. Cells stained with Annexin V-FITC indicate early apoptosis, while cells stained with PI indicate necrotic cells. Therefore, cells stained with both PI and annexin V-FITC demonstrate later stage apoptosis and early necrosis (as reported in the specifications of "Annexin V-FITC Early Apoptosis Detection Kit" from Cell Signaling Technology).

\section{Antibacterial activity}

The agar well diffusion assay verified the antibacterial activity of the optimized formulation of the clove bud oil and its emulsion (CB-4) in $S$. aureus. The mean diameter of the zone of inhibition was determined to be $15.45 \pm 0.05$ $\mathrm{mm}$ and $21.83 \pm 0.05 \mathrm{~mm}$ for clove bud oil (bottom) and its emulsion (top), respectively, as shown in Figure 10. To reinforce the findings, membrane permeability assay was conducted where considerable cytoplasmic leakage was observed through the measured absorbance values for the clove bud nanoscale emulsion system. A significant increase in the absorbance values as compared to control untreated cells indicates the loss of cell contents due to the interaction between $S$. aureus and the emulsion, as indicated in Figure 11.

B

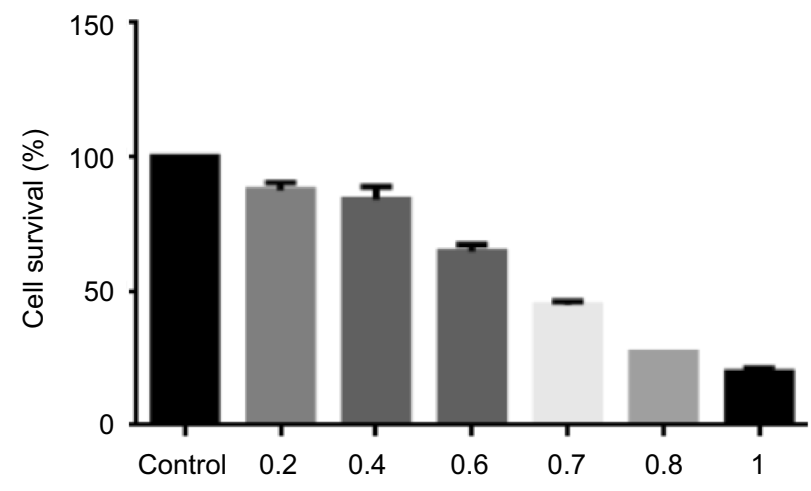

Concentration of optimized formulation $(\mu \mathrm{L} / \mathrm{mL})$

Concentration of optimized formulation $(\mu \mathrm{l} / \mathrm{mL})$

Figure 7 Effect of treatment with clove bud microemulsion on cell viability of Hek 293 (A) and HTh-7 (B) after 48 hrs incubation by MTT assay. ( $* P<0.05$ compared with respective control). 


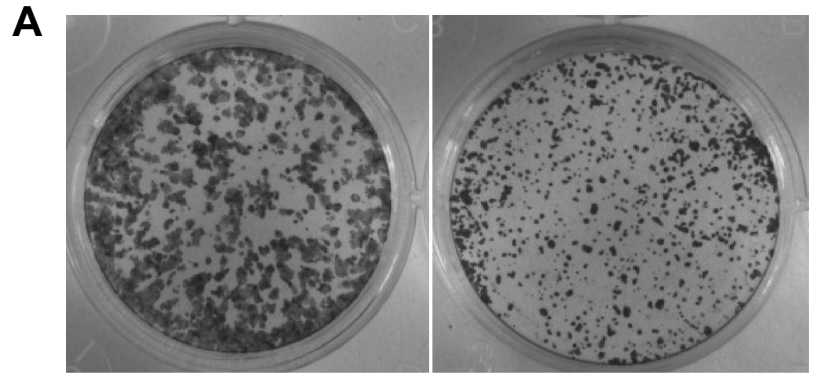

B

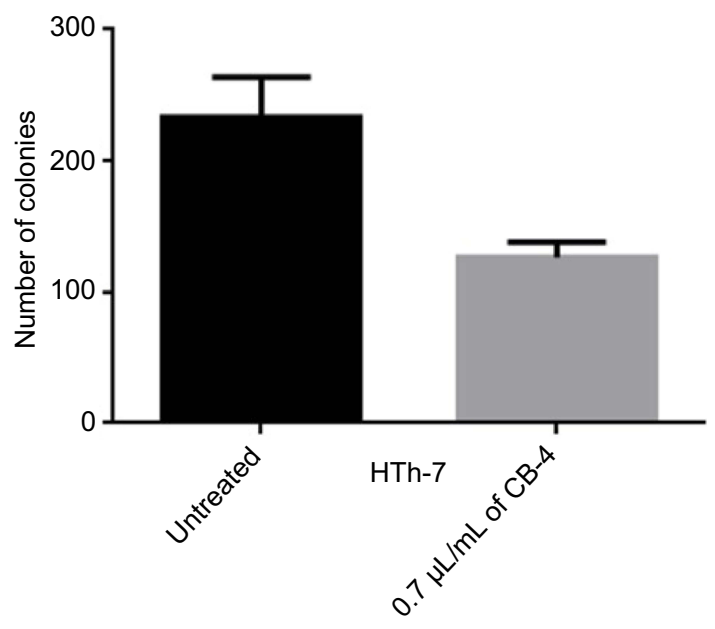

Figure 8 (A and B) Colony formation assay showing significant decrease of HTh-7 cells on treatment with microemulsion CB-4 (clove bud oil: Tween 20 ratio of 1:4; right), as compared to untreated control (left) indicating antiproliferative effect. $(* P<0.05$ compared with respective control).

\section{Discussion}

Recent studies have shown that cancer cells can survive by multiple molecular signaling pathways. ${ }^{48}$ Therefore, chemopreventive agents with antiproliferative and antibacterial effects agents must affect all pathways as compared to just one. To verify the same, formulated assays were subjected to characterization studies in order to obtain the most optimum formulation of the nanoscale emulsion of clove bud. The nanoscale system was formulated via the spontaneous self-emulsification technique using Indian clove bud oil, a non-ionic surfactant, and water. Tween 20 was chosen for further studies owing to its lower molecular weight, which enables it to easily get adsorbed on the emulsion droplet surface thereby effectively minimizing the droplet size in the emulsion. It is observed that on increasing the surfactant concentration, clear and transparent samples are formed with no phase separation owing to the negative Gibbs free energy. ${ }^{49}$ While the amount of surfactant plays an important role in the formation of a clear microemulsion, the nature of surfactant is of equal significance. Tween 20 is easily miscible with clove bud oil as compared to Tween 80 , and the difference in the HLB value of the surfactants is significant. This is attributed to the significant difference in length of the lipophilic part of the surfactant molecules. Larger micelles form in Tween 80 and prevent the formation of a monophasic region.

Turbidity of the solution was measured through absorbance. The absorbance is observed to have decreased with increase in surfactant concentration. The reduced absorbance (to near-zero values) with higher surfactant concentration is possibly due to relative weak scattering. ${ }^{50,51}$ Both $\mathrm{pH}$ and viscosity demonstrated a positive correlation with surfactant concentration. The increase in viscosity is due to the accumulation of water molecules around the hydrophilic portions of the surfactant molecule. ${ }^{52,53}$ The optimized formulation CB-4 was used for anticancer and antimicrobial studies.

MTT assay showed a decrease in cell viability in thyroid cancer line owing to the action of clove bud oil-based emulsion. Certain cancer cells obtain the capability of escaping apoptosis through various mechanisms, necessitating the application of anticancer agents to not only manipulate the apoptosis signaling pathways but also disturb their proliferation. ${ }^{54}$ Amongst many, early and selective apoptosis is considered as one of the best methods to inhibit cancer cell growth and cause death through lysis. Annexin V-FITC assay provides results to indicate later stage apoptosis and early necrosis. It is evident that the emulsion system-based cytotoxicity is contributed to a larger extent by its apoptotic nature. Treatments that cause cell death through apoptosis are preferred since they do not cause any inflammation, unlike necrosis. The antibacterial properties were evaluated using well diffusion and membrane permeability assays in $S$. aureus. The oilbased nanoscale emulsion is capable of fusing with the lipid membrane of $S$. aureus which could have caused destabilization of membrane permeability and their function, causing lysis and cell death. ${ }^{55,56}$ Structural changes in the membrane could have altered its permeability, causing significantly greater cytoplasmic leakage on treatment with clove bud nanoscale emulsion in comparison with the untreated cells. 


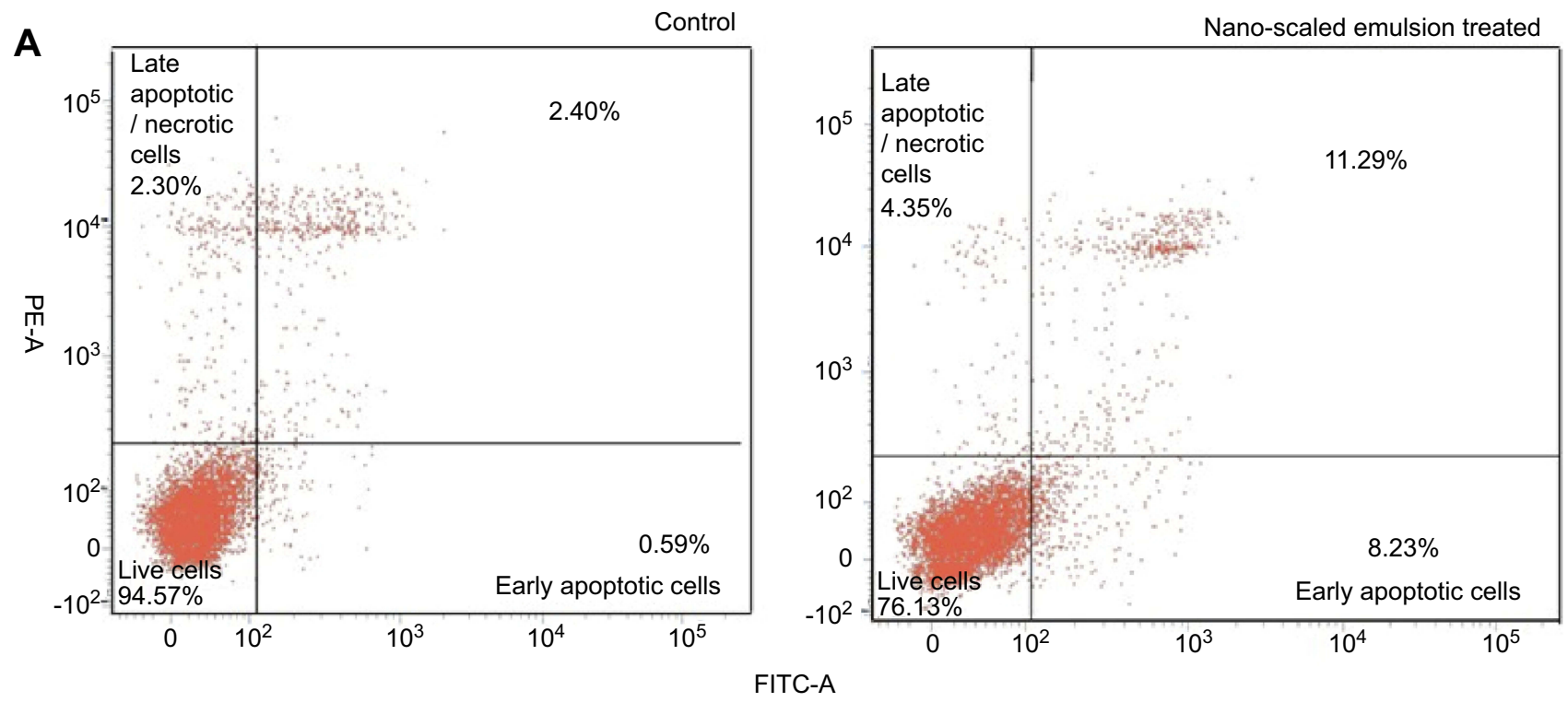

B

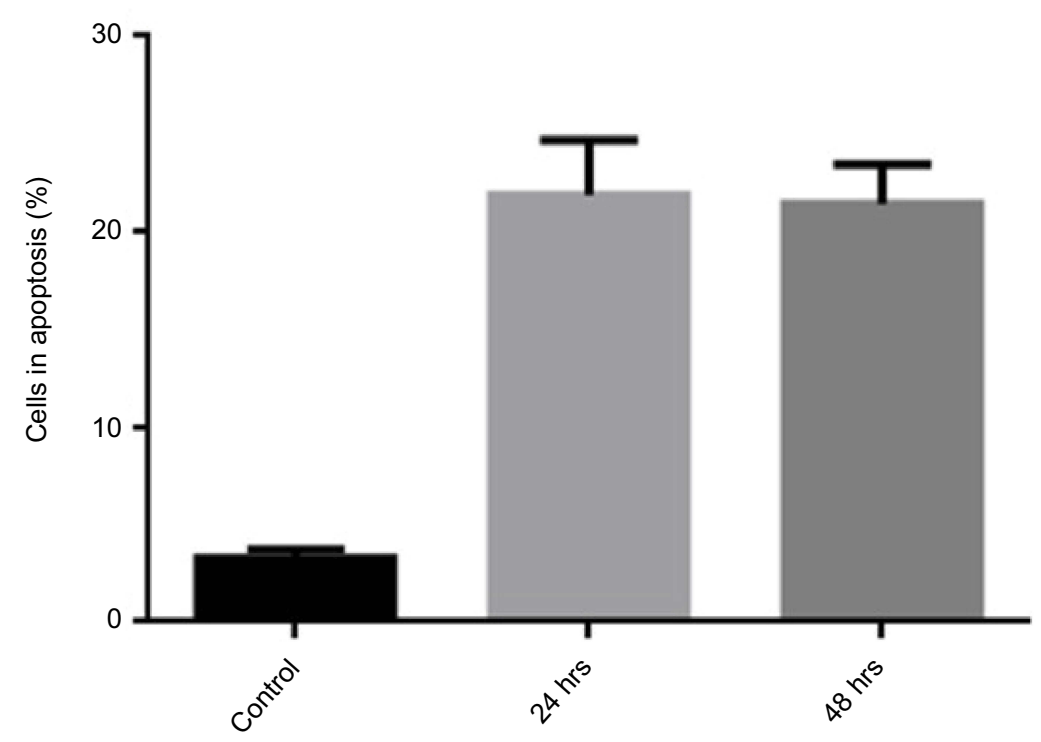

HTh-7

Figure 9 Effect of treatment with clove bud microemulsion at $0.7 \mu \mathrm{L} / \mathrm{mL}, 48$ hrs against HTh-7 cells, in comparison with control using Annexin V-FITC/PI assay showing later stage apoptosis and early necrosis.

\section{Conclusion}

The clove bud nanoscale emulsion system, produced using varying surfactant concentrations, was studied for its physicochemical characteristics and stability with the objective of identifying an optimized formulation. The cytotoxicity and antibacterial activity of such a formulation, once obtained, were assessed against the thyroid cancer cell line (HTh-7) and S. aureus, respectively. Membrane permeability studies also proved the efficacy of this optimized formulation to permeate through capillary vessels during cell lysis. The current treatment for recurrent and aggressive/anaplastic thyroid cancers is largely ineffective. Hence, it is imperative to develop novel drugs. The present formulation is the oilin-water type and meets all compliance requirements. It would therefore be of great relevance to the pharmaceutical industry. Further confirmatory tests are to be conducted through in vivo studies and clinical trials. 


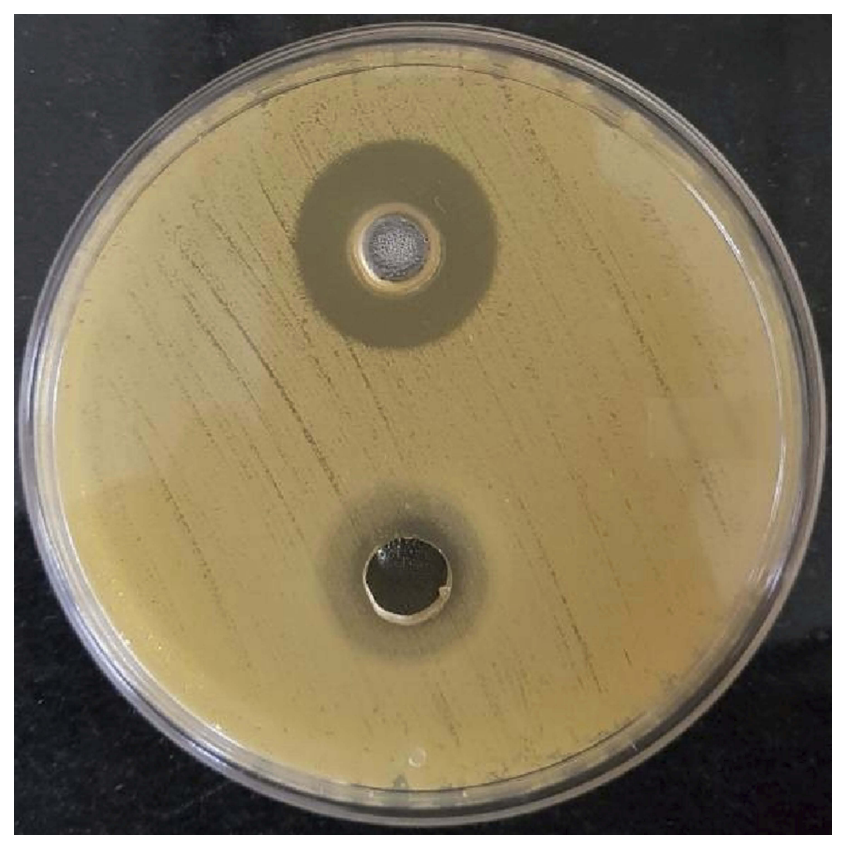

Figure 10 Well diffusion assay of Staphylococcus aureus treated with clove bud emulsion (top) and clove bud oil (bottom).

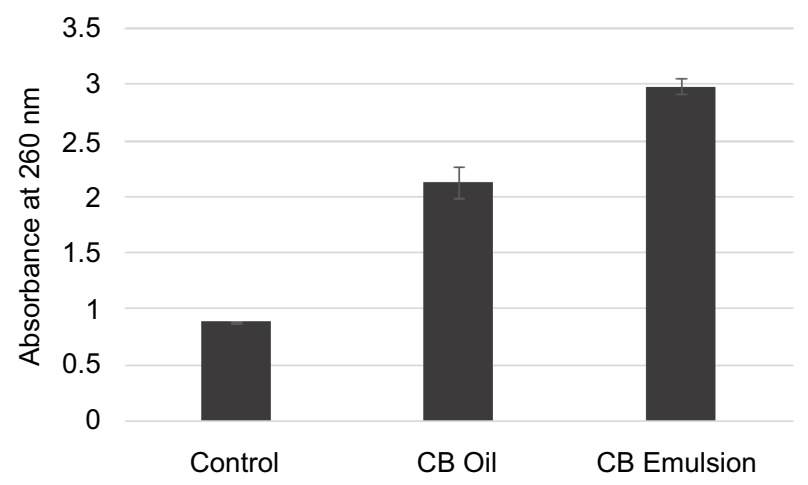

Figure II Membrane permeability study showing significant increase in the cytoplasmic leakage from Staphylococcus aureus on interaction with clove bud oil nanoscale emulsion (CB-4), as compared to untreated control cells.

\section{Acknowledgments}

We acknowledge the Central Leather Research Institute (CSIR), Adyar for providing the FACS facility. We sincerely thank Dr D. Karunagaran, head of the Department of Biotechnology, Bhupat and Jyoti Mehta School of Biosciences, IIT Madras, for allowing access to the cell culture laboratory.

\section{Disclosure}

The authors report no conflicts of interest in this work.

\section{References}

1. Reddy LA, Odhav B, Bhoola KD. Natural products for cancer prevention: a global perspective. Pharmacol Ther. 2003;99:1-3. doi:10.1016/S0163-7258(03)00042-1

2. Bray F, Ferlay J, Soerjomataram I, et al. Global cancer statistics 2018: GLOBOCAN estimates of incidence and mortality worldwide for 36 cancers in 185 countries. CA Cancer J Clin. 2018;68:394-424.

3. Naumovski L, Quinn JP, Miyashiro D, et al. Outbreak of ceftazidime resistance due to a novel extended-spectrum beta-lactamase in isolates from cancer patients. Antimicrob Agents Chemother. 1992;36:1991-1996. doi:10.1128/AAC.36.9.1991

4. Nooter K, Herweijer H. Multidrug resistance (mdr) genes in human cancer. Br J Cancer. 1991;63:663. doi:10.1038/bjc.1991.91

5. Lis-Balchin M, Deans SG. Bioactivity of selected plant essential oils against Listeria monocytogenes. J Appl Microbiol. 1997;82:759-762. doi:10.1046/j.1365-2672.1997.00153.x

6. Recio MC, Rios JL, Villar A. Antimicrobial activity of selected plants employed in the Spanish Mediterranean area. Part II. Phytother Res. 1989;3:77-80. doi:10.1002/(ISSN)1099-1573

7. Crespo ME, Jimenez J, Gomis E, et al. Antibacterial activity of the essential oil of Thymus serpylloides subspecies gadorensis. Microbios. 1990;61:181-184.

8. Pattnaik S, Subramanyam VR, Kole CR, et al. Antibacterial activity of essential oils from Cymbopogon: inter-and intra-specific differences. Microbios. 1995;84:239-245.

9. Carson CF, Hammer KA, Riley TV. In-vitro activity of the essential oil of Melaleuca alternifolia against Streptococcus spp. J Antimicrob Chemother. 1996;37:1177-1178. doi:10.1093/jac/37.6.1177

10. Nenoff P, Haustein UF, Brandt W. Antifungal activity of the essential oil of Melaleuca alternifolia (tea tree oil) against pathogenic fungi in vitro. Skin Pharmacol Physiol. 1996;9:388-394. doi:10.1159/ 000211450

11. Mitoshi M, Kuriyama I, Nakayama H, et al. Effects of essential oils from herbal plants and citrus fruits on DNA polymerase inhibitory, cancer cell growth inhibitory, antiallergic, and antioxidant activities. $J$ Agric Food Chem. 2012;60:11343-11350. doi:10.1021/jf303377f

12. Russo R, Corasaniti MT, Bagetta G, et al. Exploitation of cytotoxicity of some essential oils for translation in cancer therapy. Evid Based Complement Alternat Med. 2015. doi:10.1155/2015/397821

13. Cha JD, Kim YH, Kim JY. Essential oil and 1, 8-cineole from Artemisia lavandulaefolia induces apoptosis in $\mathrm{KB}$ cells via mitochondrial stress and caspase activation. Food Sci Biotechnol. 2010;19:185-191. doi:10.1007/s10068-010-0025-y

14. Jayaprakasha GK, Murthy KC, Uckoo RM, et al. Chemical composition of volatile oil from Citrus limettioides and their inhibition of colon cancer cell proliferation. Ind Crops Prod. 2013;45:200-207. doi:10.1016/j.indcrop.2012.12.020

15. Gomes MR, Schuh RS, Jacques AL, et al. Citotoxic activity evaluation of essential oils and nanoemulsions of Drimys angustifolia and D. brasiliensis on human glioblastoma (U-138 MG) and human bladder carcinoma (T24) cell lines in vitro. Rev Bras Farmacogn. 2013;23:259-267. doi:10.1590/S0102-695X2012005000136

16. Nanyonga SK, Opoku AR, Lewu FB, et al. Antioxidant activity and cytotoxicity of the leaf and bark extracts of Tarchonanthus camphorates. Trop J Pharm Res. 2013;12:377-383.

17. Akrout A, Gonzalez LA, El Jani H, et al. Antioxidant and antitumor activities of Artemisia campestris and Thymelaeahirsuta from southern Tunisia. Food Chem Toxicol. 2011;49:342-347. doi:10.1016/j. fct.2010.11.046

18. $\mathrm{Zu} \mathrm{Y,} \mathrm{Yu} \mathrm{H,} \mathrm{Liang} \mathrm{L,} \mathrm{et} \mathrm{al.} \mathrm{Activities} \mathrm{of} \mathrm{ten} \mathrm{essential} \mathrm{oils} \mathrm{towards}$ Propionibacterium acnes and PC-3, A-549 and MCF-7 cancer cells. Molecules. 2010;15:3200-3210. doi:10.3390/molecules 15053200 
19. Gautam N, Mantha AK, Mittal S. Essential oils and their constituents as anticancer agents: a mechanistic view. Biomed Res Int. 2014;2014 doi: $10.1155 / 2014 / 154106$

20. Gelband H, Panosian CB, Arrow KJ. Saving Lives, Buying Time: Economics of Malaria Drugs in an Age of Resistance. Washington (DC): National Academies Press; 2004.

21. Lowy FD. Antimicrobial resistance: the example of Staphylococcus aureus. J Clin Invest. 2003;111:1265-1273. doi:10.1172/JCI18535

22. Shittu AO, Okon K, Adesida S, et al. Antibiotic resistance and molecular epidemiology of Staphylococcus aureus in Nigeria. BMC Microbiol. 2011;11:92. doi:10.1186/1471-2180-11-92

23. Desbois AP, Smith VJ. Antibacterial free fatty acids: activities, mechanisms of action and biotechnological potential. Appl Microbiol Biotechnol. 2010;85:1629-1642. doi:10.1007/s00253-009-2355-3

24. Banerjee S, Panda CK, Das S. Clove (Syzygium aromaticum L.), a potential chemopreventive agent for lung cancer. Carcinogenesis. 2006;27:1645-1654. doi:10.1093/carcin/bgi372

25. Duke JA. CRC Handbook of Alternative Cash Crops. London: CRC press; 1993.

26. Fujisawa S, Atsumi T, Kadoma Y, et al. Antioxidant and prooxidant action of eugenol-related compounds and their cytotoxicity. Toxicology. 2002;177:39-54. doi:10.1016/S0300-483X(02)00194-4

27. Jadhav BK, Khandelwal KR, Ketkar AR, et al. Formulation and evaluation of mucoadhesive tablets containing eugenol for the treatment of periodontal diseases. Drug Dev Ind Pharm. 2004;30:195203. doi:10.1081/DDC-120028715

28. Gülçin İ. Antioxidant activity of eugenol: a structure-activity relationship study. J Med Food. 2011;14:975-985. doi:10.1089/jmf.2010.0197

29. Ito M, Murakami K, Yoshino M. Antioxidant action of eugenol compounds: role of metal ion in the inhibition of lipid peroxidation. Food Chem Toxicol. 2005;43:461-466. doi:10.1016/j.fct.2004.12.006

30. Kaefer CM, Milner JA. The role of herbs and spices in cancer prevention. J Nutr Biochem. 2008;19:347-361. doi:10.1016/j.jnutbio.2007.11.003

31. Pavithra B. Eugenol-a review. J Pharmaceut Sci Res. 2014;6:6153.

32. Nagababu E, Rifkind JM, Boindala S, et al. Assessment of antioxidant activity of eugenol in vitro and in vivo. Methods Mol Biol. 2010:165-180.

33. Nirmala MJ, Nagarajan R. Recent research trends in fabrication and applications of plant essential oil based nanoemulsions. J Nanomed Nanotechnol. 2017;8:434. doi:10.4172/2157-7439.1000434

34. Sutradhar KB, Amin ML. Nanoemulsions: increasing possibilities in drug delivery. Eur J Nanomed. 2013;5:97-110. doi:10.1515/ejnm2013-0001

35. Goldburg WI. Dynamic light scattering. Am J Phys. 1999;67:11521160. doi:10.1119/1.19101

36. Zhang G, Peng Y, Cui L, et al. Gold-catalyzed homogeneous oxidative cross-coupling reactions. Angewandte Chemie. 2009;121:31583161. doi:10.1002/ange.200900585

37. Morgan DM. Tetrazolium (MTT) assay for cellular viability and activity. Polyamine Protocols. Humana Press; 1998;79:179-184.

38. Yoon H, Zhang X, Kang M, et al. Cytotoxicity evaluation of turmeric extract incorporated oil-in-water nanoemulsion. Int $\mathrm{J} \mathrm{Mol} \mathrm{Sci}$. 2018;19:280. doi:10.3390/ijms19113287

39. Van Meerloo J, Kaspers GJ, Cloos J. Cell sensitivity assays: the MTT assay. Methods in Molecular Biology. 2011:731:237-245.
40. Franken NAP, Rodermond HM, Stap J, et al. Clonogenic assay of cells in vitro. Nat Protoc. 2006;1:2315-2319. doi:10.1038/ nprot.2006.339

41. Balouiri M, Sadiki M, Ibnsouda SK. Methods for in vitro evaluating antimicrobial activity: a review. J Pharmaceut Anal. 2016;6:71-79. doi:10.1016/j.jpha.2015.11.005

42. Hou L, Shi Y, Zhai P, Le G. Inhibition of foodborne pathogens by Hf1, a novel antibacterial peptide from the larvae of the housefly (Musca domestica) in medium and orange juice. Food Control. 2007;18:1350-1357. doi:10.1016/j.foodcont.2006.03.007

43. Rang MJ, Miller CA. Spontaneous emulsification of oils containing hydrocarbon, nonionic surfactant, and oleyl alcohol. J Colloid Interface Sci. 1999;209:179-192. doi:10.1006/jcis.1998.5865

44. Constantinides PP, Yiv SH. Particle size determination of phaseinverted water-in-oil microemulsions under different dilution and storage conditions. Int J Pharm. 1995;115:225-234. doi:10.1016/ 0378-5173(94)00272-7

45. Constantinides PP. Lipid microemulsions for improving drug dissolution and oral absorption: physical and biopharmaceutical aspects. Pharm Res. 1995;12:1561-1572. doi:10.1023/A:1016268311867

46. Bergantini AP, Castro FA, Souza AM, et al. Chronic myeloid leukemia and the Fas-FasL system. Rev Bras Hematol Hemoter. 2005;27:120-125.

47. Wong RS. Apoptosis in cancer: from pathogenesis to treatment. $J$ Exp Clin Cancer Res. 2011;30:87. doi:10.1186/1756-9966-30-24

48. Kamdje AH, Kamga PT, Simo RT, et al. Developmental pathways associated with cancer metastasis: Notch, Wnt, and Hedgehog. Cancer Biol Med. 2017;14:109. doi:10.20892/j.issn.2095-3941.2016.0032

49. Tadros T, Izquierdo P, Esquena J, et al. Formation and stability of nano-emulsions. Adv Colloid Interface Sci. 2004;108:303-318. doi:10.1016/j.cis.2003.10.023

50. McClements DJ. Colloidal basis of emulsion color. Curr Opin Colloid Interface Sci. 2002;7:451-455. doi:10.1016/S1359-0294(02) 00075-4

51. McClements DJ. Theoretical prediction of emulsion color. $A d v$ Colloid Interface Sci. 2002;97:63-89. doi:10.1016/S0001-8686(01) 00047-1

52. El Eini DI, Barry BW, Rhodes CT. Micellar size, shape, and hydration of long-chain polyoxyethylene non ionic surfactants. J Colloid Interface Sci. 1976;54:348-351. doi:10.1016/0021-9797(76)90314-3

53. Barry BW, Eini DE. Solubilization of hydrocortisone, dexamethasone, testosterone and progesterone by long-chain polyoxyethylene surfactants. J Pharm Pharmacol. 1976;28:210-218. doi:10.1111/ j.2042-7158.1976.tb04133.x

54. Bold RJ, Termuhlen PM, McConkey DJ. Apoptosis, cancer and cancer therapy. Surg Oncol. 1997;6:133-142. doi:10.1016/S09607404(97)00015-7

55. Zhang H, Shen Y, Weng P, et al. Antimicrobial activity of a foodgrade fully dilutable microemulsion against Escherichia coli and Staphylococcus aureus. Int J Food Microbiol. 2009;135:211-215. doi:10.1016/j.ijfoodmicro.2009.07.020

56. Baker JR, Hamouda T, Shih A, Myc A, inventors; University of Michigan, assignee. Non-toxic antimicrobial compositions and methods of use. United States patent US 6,559,189. 2003 May 6. 


\section{Publish your work in this journal}

The International Journal of Nanomedicine is an international, peerreviewed journal focusing on the application of nanotechnology in diagnostics, therapeutics, and drug delivery systems throughout the biomedical field. This journal is indexed on PubMed Central, MedLine, CAS, SciSearch ${ }^{\circledR}$, Current Contents ${ }^{\circledR} /$ Clinical Medicine,
Journal Citation Reports/Science Edition, EMBase, Scopus and the Elsevier Bibliographic databases. The manuscript management system is completely online and includes a very quick and fair peer-review system, which is all easy to use. Visit http://www.dovepress.com/ testimonials.php to read real quotes from published authors. 